\title{
Evaluation of the health-related quality of life of hematopoietic stem cell transplantation patients
}

\author{
Carla Libralli Tostes dos Santos ${ }^{1}$ \\ Namie Okino Sawada² \\ Jair Lício Ferreira dos Santos ${ }^{3}$
}

\begin{abstract}
This study evaluates the Health-Related Quality of Life of patients undergoing analogous and allogeneic transplantation at three different points in time: before, 30 and 180 days after transplantation, along with correlated clinical and socio-demographic data. Two questionnaires were used for data collection: the first addressed clinical and socio-demographic data and the second was the Functional Assessment Cancer Therapy translated and validated for Brazilian Portuguese. The initial sample was composed of 30 patients while 26 were ultimately evaluated at the three points. The set of results indicated a positive impact on Health-Related Quality of Life six months after transplantation. Despite the fact that there were additional concerns and some aspects such as physical and functional aspects were affected 30 days after the procedure, the Functional Assessment Cancer Therapy scores obtained six months after HSCT improved in all components, reaching levels above those prior to the procedure, especially physical and emotional aspects and the relationship with the physician.

Descriptors: Hematopoietic Stem Cell Transplantation; Health-Related Quality of Life; Hematologic Diseases.
\end{abstract}

\footnotetext{
${ }^{1}$ RN, Master's Student in Nursing, Escola de Enfermagem de Ribeirão Preto, Universidade de São Paulo, WHO Collaborating Centre for Nursing Research Development, SP, Brazil. Instituto Oncológico de Ribeirão Preto, SP, Brazil. E-mail: carlibra@bol.com.br.

${ }^{2}$ RN, Ph.D. in Nursing, Associate Professor, Escola de Enfermagem de Ribeirão Preto, Universidade de São Paulo, WHO Collaborating Centre for Nursing Research Development, SP, Brazil. E-mail: sawada@eerp.usp.br.

3 Physicist, Ph.D. in Public Health, Retired Full Professor, Faculdade de Medicina de Ribeirão Preto, Universidade de São Paulo, SP, Brazil. E-mail: jalifesa@usp.br.
}

Corresponding Author:

Carla Libralli Tostes dos Santos

Rua Luiza Maria Perticarrari, 170

Vila Industrial

CEP: 14177-070, Sertãozinho, SP, Brasil

E-mail: carlibra@bol.com.br 


\title{
Avaliação da qualidade de vida relacionada à saúde de pacientes submetidos ao transplante de células-tronco hematopoéticas
}

O objetivo deste estudo longitudinal consistiu em se avaliar a qualidade de vida relacionada à saúde de pacientes submetidos ao transplante autólogo e alogênico, em três momentos distintos: no pré-transplante, 30 e 180 dias pós-transplante . Para a coleta de dados, foram utilizados dois questionários: o primeiro para obtenção de dados clínicos e sociodemográficos, e o segundo constituído por uma escala específica, o Functional Assessment Cancer Therapy. A amostra inicial foi constituída por 30 pacientes, sendo 26 avaliados nos três momentos. O conjunto de resultados permitiu visualizar impacto positivo da qualidade de vida relacionada à saúde, ao final dos seis meses pós-transplante. Apesar de algumas funções se apresentarem mais prejudicadas, como a função física, funcional e preocupações adicionais com 30 dias, houve melhora nos escores do Functional Assessment Cancer Therapy em todos os componentes, chegando-se a alcançar patamares acima dos encontrados na fase do pré-transplante, especialmente nos aspectos físicos, emocionais e relacionamento com o médico.

Descritores: Transplante de Células Tronco Hematopoéticas; Qualidade de Vida Relacionada à Saúde; Doenças Hematológicas.

\section{Evaluación de calidad de vida relacionada a la salud de pacientes sometidos a trasplante de células madre hematopoyéticas}

\begin{abstract}
El objetivo de este estudio longitudinal consistió en evaluar la Calidad de Vida relacionada a la Salud de pacientes sometidos a trasplante autólogo y alogénico en tres momentos distintos: en el pre, 30 y 180 días postrasplante. Para la recolección de datos fueron utilizados dos cuestionarios: el primero para obtención de datos clínicos y sociodemográficos, y el segundo una escala específica el Functional Assesment Cancer Therapy. La muestra inicial fue constituida por 30 pacientes, siendo 26 evaluados en los tres momentos. El conjunto de resultados permitió visualizar un impacto positivo de la Calidad de Vida relacionada a la salud al final de los seis meses postrasplante, a pesar de algunas funciones presentarse más perjudicadas, como la función física, funcional y preocupaciones adicionales con 30 días, hubo mejoría en los puntajes del Functional Assesment Cancer Therapy en todos los componentes llegando a alcanzar niveles encima del pretrasplante, especialmente en los aspectos físicos y emocionales, y en la relación con el médico.
\end{abstract}

Descriptores: Trasplante de Células Madre Hematopoyéticas; Calidad de Vida Relacionada a la Salud; Enfermedades Hematológicas.

\section{Introduction}

In the past, a cancer diagnosis was a death sentence in most cases. Even today it is still associated with pain, suffering, fear of becoming dependent on others and losing one's functionality. With the advancement of technology that permits the early detection of cancer, the possibilities of treatments increasingly broaden such as surgeries, radiotherapy, and hormone therapy and also the improvement of the antineoplastic and monoclonal antibodies therapies and Hematopoietic Stem Cell Transplantation (HSCT), the chances of curing cancer and improving the survival of patients are increasingly greater.

HSCT is used for treating various malignant and non-malignant diseases. It consists of intravenously infusing stem cells intended to restore bone marrow and immune function in patients to enable increased survival 
free of disease or a complete cure ${ }^{(1-2)}$. The purpose is to graft healthy hematopoietic progenitor cells to correct a quantitative or qualitative defect of the bone marrow, allowing the production of normal blood cells in a process called hematopoiesis.

Even though HSCT has been successfully implemented there is still a significant risk of physical and psychosocial morbidity since secondary comorbidities, late side effects and death may occur(1). Morbidity related to transplantation is evident in its different phases, starting with the period prior to the transplantation and conditioning, moving toward post transplantation recovery. Cure or complete control of the underlying disease may not be followed by health recovery. Hence, the health-related quality of life (HRQOL) of survivors has emerged as an important field of study.

The patient is the best source of information concerning quality of life, which is measured and defined according to groups of patients, and may differ among the various groups according to the type of disease and the therapy secondary side effects, as well as the meaning assigned by patients to its benefits or harmful effects in the short, medium and long terms. The term 'QofL' encompasses a multidimensional concept that incorporates aspects of physical health, performance and wellbeing, that is, it is not restricted to symptoms related to the disease or its treatment ${ }^{(1)}$.

Even though QofL is a difficult term to be precisely defined, it has a meaning common to most people. It is composed of broad concepts that influence global satisfaction with life, including good health, appropriate living conditions, employment, personal and family safety, education and leisure. For issues related to health care, QofL has been specifically applied to concerns whether life is more influenced by health or disease, hence the term "health-related quality of life" (3).

Multidimensionality, subjectivity, and bipolarity are important components of HRQOL. Even though aspects such as weight loss and depression are important, there is a growing consensus that HRQOL is composed by a number of dimensions that affect one's life. Seven are mentioned $^{(4)}$ :

- Physical wellbeing - the experience of physical symptoms such as pain, dyspnea, nausea.

- Functional wellbeing - ability to perform regular daily activities such as working and leisure.

- Emotional wellbeing - composed of both positive affective states (happiness, peace of mind) and negative states (sorrow, anxiety).
- Family wellbeing - ability to maintain family relationships and communication.

- Social Functioning - ability to participate in and appreciate social roles and activities.

- Satisfaction with the treatment - including financial concerns

- Sexuality - including concern with body image.

Taking into account this multidimensionality from the point of view of health, two things can be grasped: one is directly related to health and is called Healthrelated Quality of Life (HRQOL) and then a set of factors not directly related to it such as non-medical factors, constituted of family, friendship, religious believes, work, and other life circumstances(5).

The concept of HRQOL can be defined as the value one attributes to life, weighted by functional deterioration, perceptions and social conditions induced by one's disease, morbidities, treatment and the political and economic organization of the care system. The individual's subjectivity is valued in this context $\mathrm{t}^{(6)}$.

HRQOL is the measure through which the effects of a medical condition or its treatment are seen in physical, emotional and social wellbeing. The HRQOL evaluation requires one's attention on various dimensions including physical concerns (e.g. symptoms), functional ability, family and emotional wellbeing, sexuality and social functioning. Studies concerning $\mathrm{HRQOL}$, both in the general context of a malignant disease and in the specific context of HSCT, were centered on clarifying deficits in physical, social, emotional wellbeing and wellbeing associated with cancer or cancer treatment ${ }^{(7)}$.

Patients undergoing HSCT experience multiple symptoms that may negatively affect their HRQOL. Family and work relationships may be ruptured due to the disease and prolonged treatment. Studies evaluating HRQOL of patients undergoing this therapy may be a way to evaluate the consequences of HSCT and support decision-making at the time of transplantation both for patients and the health team.

Despite the various studies addressing the HRQOL of individuals undergoing $\mathrm{HRCT}$, there are no conclusive results. Some authors agree that there is great harm after an HSCT, such as sexual dysfunction, concern with unemployment, fatigue, cognitive and psychological dysfunction ${ }^{(1,8-9)}$. Others disagree with these results showing good physical and psychological recovery after $\operatorname{HSCT}^{(2,10-13)}$.

Many studies evaluate HRQOL related to HSCT and address patients' adaptation to transplantation over the 
long term, between one and 10 years after intervention, but few address its impact during and immediately after hospitalization(2,8-13). Among prospective studies, only a few include at least one evaluation prior to the HSCT ${ }^{(12-13)}$. Prospective studies are required to evaluate more clearly the effect of these treatments related to survival in the long run ${ }^{(2)}$. Hence, this study evaluates the HRQOL of patients undergoing autologous and allogeneic HSCT in the period before intervention and 30 and 180 days after intervention.

\section{Method}

This is an exploratory descriptive prospective study with quantitative approach concerning the HRQOL of patients undergoing Allogeneic and Autologous HSCT conducted at the Day Hospital and Hospitalization unit of an oncological hospital in the interior of São Paulo, Brazil cared for between June 2008 to January 2010 after the Ethics Research Committee at the facility approved the project (Protocol 151/2008).

The sample was composed of patients who met the following inclusion criteria: patients undergoing allogeneic or autologous HSCT, being 18 years old or older at the time of data collection, presenting no recurrence of cancer or blood disease resulting from HSCT and signing a consent form after doubts were clarified.

A script was used to obtain the socio-demographic and clinical profile of patients including: age, gender, marital status, initial diagnosis, diagnostic data, pre or post HSCT and time after HSCT, type of autologous or allogeneic HSCT, type of hematopoietic stem cells, conditioning, schooling, profession, current occupation, origin, the companion's kinship, time out of home, monthly family income, other pathologies, acute or chronic graft-versus-host disease, degree and site. Data were obtained through an interview and detailed review of medical files.

The Functional Assessment of Cancer Therapy Bone Marrow Transplantation (FACT-BMT) was used to evaluate the patients' HRQOL. The FACT-BMT is a scale specific for patients undergoing HSCT, translated and validated for the Brazilian culture ${ }^{(5)}$. The FACT-BMT, third version, is composed of 47 questions, 41 of which are used to obtain the score, with the remaining six presented to provide a synthesis of information, though these should not be used to compute the final score. The questions are distributed into six domains:
- Physical wellbeing: Composed of seven questions that evaluate the presence and intensity of physical symptoms resulting from treatment.

- Social/Family wellbeing: Composed of seven questions that evaluate the relationship with family and friends and changes occurring in these relationships that arise from treatment.

- Relationship with the physician: Composed of two questions that evaluate trust placed in the physician and the relationship with him/her.

- Emotional wellbeing: Composed of six questions that evaluate symptoms.

- Functional wellbeing: Composed of seven questions that evaluate one's ability to work and perform daily activities and satisfaction with current life conditions.

- Additional concern: Composed of 12 questions that evaluate specific questions related to treatment.

FACT-BMT is scored according to each of its domains and the sum of the questions' scores. A Likert scale ranges from a score of zero (not at all) to four (vey much) for each question. Reverse scores are considered for negatively phrased questions. The FACT-BMT final score ranges from zero to 164 where higher scores represent better quality of life.

The psychometric analysis of the adapted version of the FACT-BMT revealed satisfactory internal consistency; Cronbach's alpha ranged from 0.65 to 0.88 . The construct's validity was analyzed through the correlation between the domains of the FACT-BMT and SF36 $(p<0.001)$. Significant correlations between the FACT-BMT final scores and all the SF36 domains $(p<0.001)$ showed this instrument is valid to measure quality of life associated with $\mathrm{HSCT}^{(5)}$. These results supported our choice of the FACT- BMT in this study.

Face-to-face interviews were initiated after the study was presented and free and informed consent forms were signed, taking around 20 minutes. Sociodemographic and clinical data were obtained before the FACT-BMT was applied. Data were collected at three different points in time: prior to HSCT, 30 and 180 days after HSCT.

The Statistical Package for Social Sciences (SPSS) version 15.0 was used to test the FACT-BMT's reliability and Cronbach's alpha was applied to test the instrument's internal consistency. The descriptive analysis of data (average, median, standard deviation, maximum and minimum values) and Fisher's exact test was applied in the STATA SE 11.0 to compare different points. The level of significance was fixed at $5 \%$ for all tests. 


\section{Results}

In relation to the sample's socio-demographic characteristics, the average age in the group was 40 years old, minimum of 18 and maximum of 60 years old, while there were more males (53.3\%) than females $(46.7 \%)$. The initial sample was composed of 30 individuals (both genders). Three of these died in the nursing ward and 27 remained in the immediate post HSCT phase ( 30 days after). One of the 27 patients died in the immediate post HSCT (37 days after). Hence, the evaluated sample in the three points in time was composed of 26 individuals.
The profile of the initial sample of 30 patients from the clinical point of view was that ten had a diagnosis of multiple myeloma, six had acute myeloid leukemia, six non-Hodgkin's Lymphoma, four had Hodgkin's lymphoma, two had chronic leukemia myeloid, one had acute lymphoblastic leukemia, and another had severe aplastic anemia. Regarding the type of HSCT, 19 patients underwent autologous HSCT and 11 the allogeneic HSCT.

Cronbach's alpha reliability test applied to the studied sample resulted in $\alpha=0.70$, showing that the instrument is reliable for the studied sample. The FACTBMT average scores were obtained in the three phases and then compared among them.

Table 1 - Distribution of average scores obtained in the different aspects of QofL at the different points in time: Prior to HSCT and 30 days after HSCT, according to the results obtained from the FACT-BMT

\begin{tabular}{|c|c|c|c|c|c|c|c|c|c|}
\hline \multirow{2}{*}{ Components } & \multicolumn{4}{|c|}{ Before } & \multicolumn{4}{|c|}{30 Days } & \multirow{2}{*}{$\mathbf{p}$} \\
\hline & A & SD & Min & Max & A & SD & Min & Max & \\
\hline Physical & 18.3 & 4.7 & 10.0 & 27.0 & 14.7 & 4.7 & 5.0 & 23.0 & $0.0013^{*}$ \\
\hline Socio-family & 18.9 & 4.3 & 12.0 & 28.0 & 18.3 & 4.0 & 11.0 & 26.0 & 0.2235 \\
\hline Relationship with physician & 6.9 & 1.0 & 6.0 & 8.0 & 7.0 & 1.0 & 6.0 & 8.0 & 0.7367 \\
\hline Emotional & 18.2 & 3.5 & 10.0 & 24.0 & 17.3 & 3.6 & 7.0 & 23.0 & 0.1691 \\
\hline Functional & 16.5 & 4.4 & 10.0 & 24.0 & 14.7 & 2.9 & 8.0 & 22.0 & $0.0085^{*}$ \\
\hline Additional concern & 32.8 & 4.7 & 25.0 & 43.0 & 28.9 & 4.7 & 20.0 & 40.0 & $0.0001^{*}$ \\
\hline
\end{tabular}

$\mathrm{A}=$ Average; $\mathrm{SD}=$ Standard Deviation; *Statistically significant difference

According to data provided in Table 1, there was a decrease in the patients' quality of life on all the scales' components, whereas statistical difference was observed in the physical $(p=0.0013)$ and functional $(p=0.0085)$ aspects and the additional concern category $(p=0.0001)$ 30 days after HSCT compared to the time prior to HSCT.

Table 2 - Distribution of average scores obtained in the different aspects of QofL prior to HSCT and 180 day after HSCT, according to the results obtained from the FACT-BMT scale

\begin{tabular}{|c|c|c|c|c|c|c|c|c|c|}
\hline \multirow{2}{*}{ Components } & \multicolumn{4}{|c|}{ Before } & \multicolumn{4}{|c|}{180 Days } & \multirow{2}{*}{$\mathbf{p}$} \\
\hline & A & SD & Min & Max & A & SD & Min & Max & \\
\hline Physical & 18.3 & 4.7 & 10.0 & 27.0 & 20 & 4.0 & 10.0 & 26.0 & $0.0321^{*}$ \\
\hline Socio-Family & 18.9 & 4.3 & 12.0 & 28.0 & 18.7 & 4.1 & 11.0 & 25.0 & 0.4706 \\
\hline Relationship with physician & 6.9 & 1.0 & 6.0 & 8.0 & 7.4 & 0.8 & 6.0 & 8.0 & $0.0348^{*}$ \\
\hline Emotional & 18.2 & 3.5 & 10.0 & 24.0 & 19.7 & 2.6 & 14.0 & 23.0 & $0.0206^{*}$ \\
\hline Functional & 16.5 & 4.4 & 10.0 & 24.0 & 17.8 & 3.0 & 11.0 & 22.0 & 0.0982 \\
\hline Additional concern & 32.8 & 4.7 & 25.0 & 43.0 & 32.7 & 3.8 & 24.0 & 39.0 & 0.6226 \\
\hline
\end{tabular}

$\mathrm{A}=$ Average; $\mathrm{SD}=$ Standard Deviation; *Statistically significant difference

According to data provided in Table 2, a slight improvement was observed in some components of the patients' quality of life with statistically significant differences in the physical $(p=0.0321)$, relationship with the physician $(p=0.0348)$ and emotional $(p=0.0206)$ components 180 days after HSCT compared to the period prior to HSCT. 
Table 3 - distribution of average scores obtained in the different aspects of QofL 30 and 180 days after HSCT according to the results obtained in FACT-BMT

\begin{tabular}{|c|c|c|c|c|c|c|c|c|c|}
\hline \multirow{2}{*}{ Components } & \multicolumn{4}{|c|}{30 days } & \multicolumn{4}{|c|}{180 days } & \multirow{2}{*}{$\mathbf{p}$} \\
\hline & AV & SD & Min & Max & A & SD & Min & Max & \\
\hline Physical & 14.7 & 4.7 & 5.0 & 23.0 & 20 & 4.0 & 10.0 & 26.0 & $0.0000^{*}$ \\
\hline Socio-Family & 18.3 & 4.0 & 11.0 & 26.0 & 18.7 & 4.1 & 11.0 & 25.0 & 0.1634 \\
\hline Relationship with physician & 7.0 & 1.0 & 6.0 & 8.0 & 7.4 & 0.8 & 6.0 & 8.0 & 0.0672 \\
\hline Emotional & 17.3 & 3.6 & 7.0 & 23.0 & 19.7 & 2.6 & 14.0 & 23.0 & $0.0026^{*}$ \\
\hline Functional & 14.7 & 2.9 & 8.0 & 22.0 & 17.8 & 3.0 & 11.0 & 22.0 & $0.0003^{*}$ \\
\hline Additional concern & 28.9 & 4.7 & 20.0 & 40.0 & 32.7 & 3.8 & 24.0 & 39.0 & $0.0004^{*}$ \\
\hline
\end{tabular}

A=Average; SD=Standard deviation; *Statistically significant difference

According to data provided in Table 3, a statistically significant improvement was observed in all the participants' QofL components: Physical $(p=0.0000)$, emotional $(p=0.0026)$, functional $(p=0.0003)$ and additional concern $(p=0.0004), 180$ days after HSCT compared to 30 days after HSCT.

\section{Discussion}

HSCT was successful and resulted in a large number of survivors who became free of the disease. The big question that emerges for HSCT candidates is "how is one's quality of life after the procedure?" HSCT is indicated for malignant or non-malignant pathologies, changing the prognosis of patients with diseases that not so long ago were considered fatal. However, it is an expensive and aggressive procedure with high rates of morbidity and mortality, resulting in severe side effects and other complications that interfere in the quality of life of patients.

The results of this study show that the HRQOL of patients is greatly compromised immediately after the procedure (30 days after), recovers 180 days after the procedure, reaching slightly higher levels compared to the period prior to HSCT and corroborate various studies reporting that the variable "time" is positively correlated with most aspects of HRQOL ${ }^{(10,14-16)}$.

Patients receive high doses of chemotherapy and radiation during hospitalization due to HSCT, which requires a long period of hospitalization, isolation, physical changes and toxicity that threaten life, causing anxiety and depression ${ }^{(17)}$.

Harm caused to HRQOL in the first year after HSCT is demonstrated in one study ${ }^{(18)}$ addressing 152 patients after undergoing HSCT. The content analysis of the interviews revealed three affected areas: 1) physical problems including fatigue, physical appearance, eating problems and physical restrictions; 2) psychological problems such as fear about the future, loss of control, anxiety and depression; 3) reintegration problems that included difficulties resuming social roles, separation from home, family and friends and financial hardships.

Other studies ${ }^{(16,19)}$ also show that the HRQOL of patients can also significantly suffer in the first year after HSCT given potential physical and psychological sequelae such as GVHD, fatigue, depression and fear of recurrence.

The conclusion is that the variable "time" is related to higher scores in HRQOL domains, since patients with more time after HSCT present gradual improvement of their organic condition, reduced limitations accruing from the treatment such as an impossibility to perform activities involving physical effort, regular use of medications, frequent ambulatory return visits, and potential recurrence of the disease ${ }^{(5,16)}$.

\section{Conclusion}

A transplanted individual experiences either cancer or other hematological diseases that lead to transplantation. The aggressive treatment keeps this individual distant from home, family, daily activities such as work, and under threat of potential complications, in addition to fear related to recurrence and death.

The set of results presented permitted us to observe a positive impact on HRQOL in patients with neoplasia and other hematological diseases undergoing HSCT at the end of six months after HSCT. Even though some aspects, such as the physical and functional aspects, are more compromised 30 days after HSCT and patients experience additional concerns, the FACT-BMT scores obtained six months after HSCT improved in all the components, even reaching higher levels compared to the period prior to HSCT, especially in physical and emotional terms and in relationship with the physician.

Even though the low number of subjects is considered a limitation in this study, its results corroborate those in the literature, showing the importance of studies of this nature identifying the effect of HSCT on the HRQOL of patients undergoing this procedure. Identifying the 
treatment implications supports decision making of the interdisciplinary team and patient as she/he undergoes this highly complex procedure, as well as helps the planning of care aimed to alleviate symptoms and strategies to improve the functionality of these patients.

HRQOL is an important measure of outcomes in clinical studies and prospective studies provide followup results with an expectation to improve the patients' HRQOL before and after they undergo HSCT. For that, one has also to consider the importance of choosing a reliable HRQOL instrument based on the studied sample. Such a choice has to be carefully considered to detect relevant differences in the life of each patient in particular, since data can affect results and conclusions.

\section{References}

1. Andrykowski MA, Greiner CB, Altmaier EM, Burish TG., Antim JH, Gingrish R, et al . Quality of life following bone marrow transplantation findings from a multicentre study. Br J Cancer. 1995;71:1322-9.

2. Sutherland HJ, Fyles G.M, Adams G, Hao Y, Lipton $\mathrm{JH}$, Minden MD, et al. Quality of life following bone marrow transplantation: a comparison of patient reports with population norms. Bone Marrow Transplant.1997;19(11):1129-36.

3. Cella DF. Measuring quality of life in palliative care. Semin Oncol. 1995;22(2):73-81.

4. Kornblith $A B$, Holland JC. Handbook of measures for psychological, social, and physical function in cancer Quality of life. New York: Memorial Sloan-Kettering Cancer Center; 1994.

5. Mastropietro AP, Oliveira EA, Voltarelli JC, Santos MA. Functional Assessment of Cancer Therapy Bone Marrow Transplantation: tradução e validação. Rev Saúde Pública. 2007;41(2):260-8.

6. Auquier P, Simone MC, Mendizabal H. Approaches theoriqués methodologiqués de lá quatité de vie lieé à la santéa. Revue Prevenir. 1997 ;33:77-86.

7. Andrykowski MA, Bishop MM, Hahn EA, Cella DF, Beaumont MJB, Horowitz MM, et al . Long-Term HealthRelated Quality of Life, Growth, and Spiritual Well-Being After Hematopoietic Stem-Cell Transplantation. J Clin Oncol. 2005;23(3):599-608.

8. Bush NE, Haberman M, Donaldson G, Sulivan KM. Quality of life of 125 adults surviving 6 to 18 years after bone marrow transplantation. Soc Sci Med. $1995 ; 40(4): 479-90$.

9. Kiss TL, Abdollel M, Jamal N, Minden MD. Long-term Medical Outcomes and Quality-of-Life Assessment of Patients with Chronic Myeloid Leukemia Followed at least
10 years after Allogeneic Bone Marrow Transplantation. J Clin Oncol. 2002;20(9):2334-2343.

10. Chiodi S, Spinelli S, Ravera G.. Quality of Life in 244 recipients of allogeneic bone marrow transplantation. $\mathrm{Br}$ J Haematol. 2000;110(3):614-9.

11. Baker KS, Gurney JG, Ness KK. Late effects in survivors of chronic myeloid leukemia treated with hematopoietic cell transplantation: results from the Bone Marrow Transplantation Survivor Study. Blood. 2004;104(6): 1898-906.

12. Kopp M, Schweigkofler $H$, Holzner B, Nachbaur D, Niederwieser D, Flleishacker WW, et al. EORTC QLQ-C-30 and FACT-BMT for the measurement of quality of life in bone marrow transplant recipients: a comparison. Eur J Haematol. 2000;65(2):97-103.

13. Duell $T$, Van Lint MT, Ljungman P, Tichelli A, Socie G, Apperley JF. Health and functional status of longterm survivors of bone marrow transplantation. EBMT Working Party on Late Effects and EULEP Study Group on Late Effects. European Group for Blood and Marrow Transplantation. Ann Intern Med.1997;126:184-92.

14. Prieto JM, Atala J, Blanch J, Carreras E, Rovira M, Cirera E, Gasto C. Patient-rated emotional and physical functioning among hematologic cancer patients during hospitalization for stem-cell transplantation. Bone Marrow Transplant. 2005;35:307-14.

15. Fife BL, Huster GA, Cornetta KG, Kennedy VN, Akard LP, Broun ER.. Longitudinal study of adaptation to the stress of bone marrow transplantation. J Clin Oncol. 2000;18:1539-49.

16. Kopp M, Schweigkofler H, Holzner B, Nachbaur D, Niederwieser $D$, Flleishacker WW, et al. Time after bone marrow transplantation as an important variable for quality of life: results of a cross-sectional investigation using two different instruments for quality-of-life assessment. Ann Hematol. 1998;77:27-32.

17. Pallera,AM, Schartzberg,LS.Managing the toxicity of hematopoietic stem cell transplant. J Supp Oncol. 2004;2(3)223.

18. Baker F, Zambora J, Polland A, Wingard J. Reintegration after bone marrow transplantation. Cancer Pract.1999:7(4):190-6.

19. McQuellon RP, Russell GB, Rambo TD, et al Quality of life and psychosocial distress of bone marrow transplantation recipients: the time trajectory to recovery over the first year. Bone Marrow Transplant. 1998:21:477-86. 